\title{
Proceeding
}

Supplementary Issue: Summer Conferences of Sports Science. Costa Blanca Sports Science Events, 25-26 September 2020. Alicante, Spain.

\section{School, sport and fair play}

\author{
SALVATORE PIGNATO ${ }^{1}$, VITTORIA PATANIA $^{1}$, FRANCESCO CASOLO², MANUELA VALENTINI ${ }^{3}$ \\ ${ }^{1}$ Faculty of Human Sciences and Society, University of Enna Kore, Italy \\ ${ }^{2}$ Faculty of Education, Catholic University of the Sacred Heart of Milan, Italy \\ 3Department of Humanities, University of Urbino "Carlo Bo", Italy
}

\begin{abstract}
The intervention develops the concept of fair play and the educational potential of sport as an observation point of social change taking place, through a re-reading of the sociological and pedagogical analysis of the notion of sport. The contribution focuses on the ethical dimension of dialectic between the cultural value of sport, competition and the morality of the human limit, in light of the main international documents that addressed the relationship between sport and ethics. Characteristic of youth sport is to overcome this limit in accordance with the universal principles of truth and loyalty, oriented to sportspersonship, based on the promotion of the person, indispensable to the comparison with themselves and with others, supported through the promotion of contexts inclusive educational education. Sport, after the family, is a formidable educational context of relationship, where children can learn and consolidate correct and pro-social behaviours. Resuming reading the latest National Indications of MIUR and Skills Development Achievements, The study highlights the thematic cores of gaming, sports, rules and fair play, which are the basis of the educational model of physical education in primary school, clarifies how youth sport, if practiced well, can affect the overall formation of the person and can reconnect the virtuous circuit between the collective interests of the community and those of individuals.
\end{abstract}

Keywords: School; Sport; Fair play; Sportspersonship; Education; Ethics.

\section{Cite this article as:}

Pignato, S., Patania, V., Casolo, F., \& Valentini, M. (2020). School, sport and fair play. Journal of Human Sport and Exercise, 15(4proc), S1169-S1177. doi:https://doi.org/10.14198/jhse.2020.15.Proc4.18

\footnotetext{
Corresponding author. Faculty of Human Sciences and Society, University of Enna Kore, Italy.

E-mail: salvatore.pignato@unikore.it

Abstract submitted to: Spring Conferences of Sports Science. Costa Blanca Sports Science Events, 19-20 June 2020. Alicante, Spain.

JOURNAL OF HUMAN SPORT \& EXERCISE ISSN 1988-5202

(C) Faculty of Education. University of Alicante

doi:10.14198/jhse.2020.15.Proc4.18
} 


\section{INTRODUCTION}

Sport represents an extraordinary observation point in terms of social changes. In the first half of the nineteenth century, the Homo Ludens (Huizinga, 2002), focuses on the central cultural position of sports games as a key element of social life. Sport, in general, represents a high expression of civilization and while highlighting the unspoken needs of each historical phase, it explains the reasons for sociability, sense of identity, people cohesion and belonging of individuals to a specific community. However, very often, owing to the possible foolishness of sports events, the Dutch historian sees in modern sport, unfolding its effects on the growing mass society, the signs of a crisis caused by loss of clarity of mind and the happening of events less and less comprehensible on rational basis, exaggerated by the obsessive control of mass communication systems.

Analysing the theme of the relationship between modernity and sport, Elias (1985) says that modernity diffuses in Europe also due to a new social system made of habits, attitudes and lifestyles completely different from the past. Sport witnesses this process and goes along with it. It represents one of those dimensions through which the evolutionary process of civilisation takes hold, becoming a natural and spontaneous laboratory which allows to observe the evolution in social relationships, and the binding between competition and cooperation, excitement and self-control. Modern games and team sports by which it is characterised for its diffusion and general consent, represent a landmark for that civilising process, transforming the aristocratic lousier into competitive practices sustained by rules. The team which is obliged to observe the rules in order to win, is similar to States in modern European societies that, in their continuous process of self-regulation, monopolise citizens' lives. At the very centre of Elias's theoretical construction there is the process by which the European ruling classes would impose new social models to the communities: from fashion to lifestyles, from production to work as well as educational and social models.

Therefore, the evolution of the game and the complexity of modern sport represent the epiphenomenon of social models based on the urgent need of controlling emotions, regulation of instinct expressions, respect of rules, codes, and laws. In other words, the capitalistic control and its forms of oppression on mind and bobby, physical and intellectual abilities, exercise a social control which the organisation of free time, games and sport can't elude. At the end of the last century, changes in the sports event grow further and are analysed in the perspective of the most general transformations in modern society. A great attention is paid to the connections which sport contributes to create in society, to contain bad social behaviours, promoting fair play, fairness, self-confidence, respect of the adversary, up to the engagement against violence, xenophobia and racism (Federici, Cocco, 2020). According to the Weberian model of the relationships between microcosms and macrocosms, Guttmann (1994) catches the essential characteristics of contemporary sport, understanding the various steps it has gone through since early times. While ancient sport was mainly characterised by religious and warlike rituals, it is currently characterized by specialisation and rationalisation, bureaucratic organisation, quantification, exhibition-like and competition processes.

The divide is represented by the exasperation of its representations: first of all, the absolute search of records and profits in the competitive activities which were not known in the ancient, medieval and modern times. In this way, at least, it's clearly possible to distinguish real sport from recreational-sporting games, which, although requiring physical and intellectual commitment, have an important nonutilitarian function, to build a constructive correlation between sport and education. Precisely for its educational potential, nonutilitarian and competitive sport must supply a clear and unequivocal positive reference background to those who directly or indirectly refer to it, embodying positive values and resisting to the negative inner and external pressures which obscure its educational aims (Pignato 2019). Barthes (2007) says that to practice a sport 
does not mean only living, suffering, hoping, understanding but also above all expressing one's feelings with the voice, the gesture, the face, means taking the whole world as a witness, in a word, communicating. There are also forces, conflicts, joys, anxieties in man: sport expresses them, frees them, burns them, never allowing them to destroy anything. Sport in its multiplicity of functions has a role that can be educational or uneducative, with respect to its positive or negative effects on the behaviour of the people who follow it (many) and practice it (few). Heinemann (1996) offers us a key to understanding that is consistent with the modernization process. Contemporary sport is characterized by a process of growing differentiation, which, depending on the characteristics and the different dimensions in which it takes place, legitimizes sporting activities and motivates participants to dedicate time and resources to sporting activity. Indeed, Heinemann distinguishes contemporary sport in four models: competitive, expressive, instrumental and spectacular. Models not in their own right, but often capable of unconscious contamination. The competitive model of sport pursues the aims of traditional sport. It therefore makes use of a rigid and universal regulation for all participants, of a uniformity of the system of values, within which it has not long taken shape and a series of activities are developed that can be linked to the notion of fair play. Legitimation is postulated by the objectives achieved or intended to be achieved.

The sport identified in the expressive model is the result of the great changes that took place in society at the end of the last century, which produced, especially in advanced Western societies, a new and diversified way of producing goods, goods and services, causing a strong cultural change. a change in the rhythms and habits of work, a substantial modification of the increased availability of free time. Furthermore, the increase in wealth, the enhancement of the body and the interest of the media have favoured the participation of previously excluded subjects (women, elderly, disadvantaged subjects). Sports activities, as a consequence, have in turn seen important transformations (Raiola, 2020a). The changes require a new training strategy in the academic field, with particular reference to the necessary innovation in teaching and the methodologies of motor sports disciplines (Raiola, 2020b; D'Elia, 2019). The setting of sports activities has undergone a disruptive change of scenery: from indoor to outdoor. Nature is at the centre of physical and sporting activity. In this direction, several and important are the most recent contributions of research in Italy (Monti et al., 2019b) which have particularly concerned physical activity developed between indoor contexts, physical education and the consequent growth the levels of self-esteem, resilience, psychosocial empowerment of the participants (Russo et al., 2019a).

According to Heinemann, the affirmation of post-industrial social and economic models develops the instrumental model of sport associated with wellness points equipped with sophisticated machines: spin bikes, steppers, indoor rowing, body planet, etc. The interest is exclusively linked to the importance of physical form to exhibit one's body considered the only means of identity. The increasingly widespread activities of High Intensity Interval Training are a typical expression of that model. The prototype of the sport show aimed at entertainment has experienced an unprecedented expansion in the current era, in close relation to the market circuits and the centrality assumed by the mass media. In 1934, Lewis Mumford, following the logical trace of the disenchantment of sport present in Huizinga's works, had highlighted a particular aspect of the sporting world, precisely the spectacular dimension and the consequent downgrading of the sporting event, in simple satisfaction of needs considered trivial and intolerant, which will prove to be predictors of the individual-mass (Greco, 2004) and which will sanction the end of the educational value of sport. On the contrary, PJ Arnold (2002) affirms the concept of educational quality of sport and motor-sports education at school, in the sense that "sport, like physical education, is fundamentally connected with the moral sphere no less than with the rational one. Sport, at least insofar as it values the promotion of practical competence and moral behaviour, is educational". He sees in fair sporting practice an essential link between 
sport and education, the foundation of the more general idea of the good as an ontological, gnoseological and normative and therefore regulative principle of the community (Farinelli, 2005).

\section{SCHOOL, MOTOR SPORTS EDUCATION AND FAIR PLAY CULTURE}

The Olympic Charter in article 2 states that in associating "sport with culture and education, Olympism aims to create a lifestyle based on the joy of effort, the educational value of good example and respect for the principles universal fundamental ethics". History has taken on the task of demonstrating the contradictions and fallacy of those claims and how far we still need to travel to reach that goal, not only in relations between states. The news often reports daily events related to non-competitive sport whose protagonists, young and old, are at the centre of very serious episodes of aggression, oppression, real violence. To spread the principles of fair play in sports practice, in 1963 the CIFP, International committee for fair play, set out to spread the observance of the rules, respect for the opponent, the rejection of violence and incorrect behaviour of athletes. In 1975, the European Charter of Sport for All, issued by the Council of Europe, states that sport, "in order to fulfil its educational, cultural and social functions, must be organized and practiced on the basis of scientifically based principles and criteria, in compliance disciplinary rules, shared and freely accepted rules of fair play, and the needs of citizens". We will have to wait until 1992 to have a Code of Sports Ethics approved by the Council of European Ministers responsible for Sport, gathered in Rhodes for their seventh conference.

The fundamental principle of the Code, expanding the boundaries of the application of the concept of sporting loyalty, emphasizes that the ethical considerations inherent in "fair play" are not optional, but essential elements in every sporting activity, in every phase of the policy and management of the sports sector, applicable to all levels of skill and sporting commitment, from recreational to competitive. The main interest of the Code of Ethics is the fair play of children and young people, in recognition of the fact that it is they who have the right to practice a sport, deriving satisfaction and psycho-physical well-being, with the responsible assistance of institutions and irreplaceable adults. in promoting fair play and in guaranteeing respect for rights. The Code assigns fair play a broad meaning that goes far beyond the narrow notion of "fair play". It refers to the need to give children a sporting experience that encourages them to participate in healthy physical activity throughout their life; to avoid simplistically treating children as little adults; to be aware of both the physical and psychological transformations involved in youth maturation and the influence of these changes on sports performance; to avoid arousing expectations in the child that are disproportionate to his possibilities; to highlight the pleasure and satisfaction of playing sports without exerting pressure contrary to the child's right to choose; to adopt safeguard measures to prevent the exploitation of children, particularly those who demonstrate precocious aptitudes. "Fair play is a way of thinking, not just a way of behaving. It also includes the fight against cheating, against tricks bordering on the rule, the fight against doping, violence (both physical and verbal), exploitation, inequality of opportunities, excessive commercialization and corruption".

Fair play is a positive concept that promotes and develops sport and participation and offers the individual the opportunity to get to know themselves, interact with others, have fun, develop technical skills and achieve personal success. Concepts reaffirmed in 2004 in the Declaration of Panathlon International on ethics in youth sport, which incorporates the principles of the Charter of Children's Rights to Sport formulated by the UN in conjunction with the holding of the 10th World Congress of Sport for All in Rome. The declaration in point 5 states, among other things, that practicing a sport is first and foremost fun and a game; that you have the right to be trained by competent people, respecting age, personal dignity, individual skills. The school must represent the driving force for the promotion of fair play not only in sporting activities but in all the 
dimensions through which the educational and training process is expressed. The school is the elective place for cultural promotion and education of the concept of authentic sport capable of giving those who practice it specific skills in terms of self-control, moral tension, loyalty, generosity and self-denial, courage and discipline, a sense of responsibility and fairness, the promotion of behaviours oriented towards fairness and proactivity Federici \& Cocco, 2019; Pignato, 2019).

The still unfinished parliamentary process that introduces physical education in Primary School represents an important step which, if well implemented and managed, can give new answers related to the issues of sport, movement and education (Tortella et al, 2019). The EF in Primary School, in fact, establishes after years of delays and improvisations, that movement is the basis of the formation of the child's personality; movement education contrasts bad lifestyles; ludo-motricity, sport and competition in educational contexts favour cognitive, social and affective experiences and promote knowledge and respect for ethical values that are the basis of civil coexistence and are indispensable for exercise of active and conscious citizenship (Tortella \& Fumagalli, 2017).

A change in strategy that requires a radical change in the objectives and contents of physical education in primary school (Delia, 2020). From fair play in sport to fairness and loyalty in everyday life. The concept of fair play has timidly entered school practice, starting with legislative and regulatory production, with increasingly explicit and precise references, starting from the Ministerial Decree February 9, 1979. The law refers to fair play without citing it when it states that "the respect that must always be expected of the rules of sport or of the game - whether they are codified or freely 'teaching and school environment". This leads us to clarify that competitive spirit, understood as a commitment to give the best of oneself in comparison with others, is part of the logic of education and therefore of the school. The reform of the Elementary School $n$. 104 , of February 12, 1985, in explaining the aims of physical education (education aimed at grasping the new cultural meanings of corporeality, movement and sport on a personal and social level was defined) also proposed the achievement of the aim of promoting "coherent relational behaviours by verifying the need for rules and respect for the rules, lived in gaming and sports start-up experiences, also developing the capacity for initiative and problem solving". In the National Indications for Personalized Study Plans in Lower Secondary School, sports activities continue to keep a low profile. In physical education, the topics related to sporting activity as an ethical and educational value remain important statements. The theme of "fair play" and, above all, the didactic and methodological commitment carried out in practice at school still remained in the background, did not translate into active practices with specific didactic interventions and consequent methodological choices.

The irruption of a very serious news event, which occurred in Italy at the Cibali stadium just after the end of the Catania - Palermo football match on February 2, 20007, forced the IP minister to reiterate with a provision issued just 7 days after the events of violence, a series of interventions against the school system. Starting from the assumption that "physical activity and sporting practice, through correct interdisciplinary action, contribute to the harmonious development of the person and to the promotion of the culture of legality through the practice of respect for others, rules and fair play [ ...] every effort must also be made by the school which has the responsibility of educating young people to the culture of legality and non-violence, to ensure that the practice of a sport is aimed at arousing deep passion, desire to have fun and have fun". The school was assigned some specific tasks in terms of education to legality, the culture of non-violence, respect for the opponent in the game, fair play. The main aspects of the intervention of the school, starting with Primary, were centred, in particular, on the dissemination of sports culture, to develop a new sports and ethical awareness based on mutual respect, civil coexistence, life education, school-family connection to educate parents in behaviours centred "on the culture of physical education and sport as a moment of training, 
education for health and well-being, growth and socialization and not a mere battle for victory and results". In high school courses, governed by the D.P.R. 15 March 2010, n. 89, the theme of sport, rules and fair play becomes part of the learning objectives. The student must be educated to promote skills that allow him to "face the competitive confrontation with correct ethics, with respect for the rules and true fair play".

The theme of the educational value of fair play is present in the teaching of physical education in high school courses, in the sense that it is not limited to exercising individual or team physical skills. Participating in various physical activities through sport allows you to know and fully understand principles and concepts inherent to the "rules of the game", fair play, respect, tactical and body awareness, personal interaction and team commitment. The Targets for the development of skills in the 2012 National Indications already envisage at the end of the first cycle, the achievement of specific skills achievable through physical education developed in the thematic core of games, sports, rules and fair play, in which the major issues of the value of rules and the importance of respecting them; to be willing to implement collaborative and participatory behaviours; to be able to manage competitive situations, in and out of the competition, in which self-control skills and respect for each other are required, both in the event of victory and in case of defeat. The orientation process conducted through the pedagogical canons of sport education strengthens the promotion of social skills essential for proper social relationships, such as tolerance, social cohesion, inclusion, competition, agency, fairness. The didactic models, indicated by Siedentop (1994), built through structured sport-play at school, go in this direction. In this context, sport at school positively affects learning, as can also be deduced from the essay by Sgrò et al. (2020), which recorded the positive outcomes on the learning outcomes of students during a cycle of volleyball lessons. The practice of sports activities at school. By encouraging the promotion of good sports practices, they directly influence the social skills of students, indirectly providing the essential tools to promote responsible leadership, to educate to work towards common goals, to strengthen decision-making skills, all central educational goals in training. of the person, even if the results cannot always be defined as encouraging (Sandford et al., 2006).

In general, for some years now, sports experience in the educational field has been considered positive from the point of view of the more overall social impact and psycho-physical well-being. The WHO program (20162025) recommends the practice of adequate levels of physical activity for children aged 5 to 17 (at least 60 minutes per day of moderate-vigorous activity, including at least 3 times a week strength exercises, which may consist of movement games or sports activities) as a necessary condition for the development of basic cognitive, motor and social skills. You have to start from primary school. In this direction, the "Sport in the classroom" project, despite the conceptual limitations of a failure to accept the most innovative educational needs connected to the modern concept of the relationship between body and movement, education and curriculum, represents the only gateway to the School Primary Physical Education. What is needed for primary school is not a "new teaching" to be associated with the curriculum, but rather the initiation of a broad and profound educational process through didactics and methods of motor-sports education, which favours harmonious integration between and body across the curriculum. It is with this aim that motor education must enter the school curriculum, because it does not represent an almost episodic and fluctuating additional component, but rather a structural and irreplaceable component, based primarily on natural and playful motor skills. The educational dynamics, connected to the tradition of active schooling, as rightly emphasized in the essay by Schembri et al. (2019), allow to increase the level of motor competence in children which will positively reflect on the overall learning process.

The aim of motor sports activity at school is important and, therefore, the school must reconsider the pedagogical function of sport in the educational field, starting with the design of the aims and educational strategies and enhancing the competence and professionalism of the education teacher physics, taking into 
account that in recent years university education has helped to better define profiles, tasks and roles. Precisely because motor-sport activities move within a proactive relationship exchange, the competent physical education teacher has didactics, methods, tools useful for grasping in advance the problems, trends, and relationship difficulties of the students and engage them to confront themselves, to respect their limits, to treasure failure and defeat in sport as in life. Making physical education a teaching based on skills, effectively integrated with other curricular disciplines is an important step, which must increasingly connect with the action carried out by sports clubs, technicians and coaches, so that the educational process in its complexity is effectively balanced, capable of contributing to forming responsible citizens, who look to fair play as a generative model of correct social relations.

\section{CONCLUSION}

In the latest essay published shortly before his death, Bauman (2018), faced with the question of whether it is still possible to think ethically and endow oneself with a shared and shareable morality, affirms that it is impossible to revitalize the old foundations of ethics and to overcome the uncertain times in which society is ready to live, it is necessary to rediscover the connections between the collective interests of the community and the interests of individuals. "Sharing responsibilities would help many citizens to recover the voice they have lost or have given up making heard. Contemporary society is characterized by a plurality of voices and by now we know that it will be so for a long time. The central question of our age is to make this polyphony harmonious and prevent it from degenerating into cacophony". The need for ethics is an objective fact to allow adequate social connection and it seems to us that sport belongs fully to that polyphonic orchestra to which Bauman referred. It is undeniable that sport necessarily materializes in reality through adequate physical and athletic preparation, the ability to resist fatigue, the search for technical perfection to overcome oneself and others.

Sport cannot be asked to abdicate these values. Instead, it must be expected that it renounces to achieve results and records without due consideration of the moral values, foundations of both professional and amateur sports, which concern not only the conduct of sportsmen, but of all interested parties including families. of athletes, especially young ones. The ethics of sport cannot, in fact, be reduced to compliance with federal regulations, but is substantiated in shared values and behaviour. The border to cross is between sport that looks after the result and to achieve it everything becomes lawful and sport as a social practice, promoting well-being for individuals and for society. It is therefore a question of going beyond the fair play of the rules, to move from an abstract and elitist vision to a conception that tunes it to the problems of our time, making sporting practice, from school to competitive, the promoter of a new horizon in which the logics that favour wild competition are defeated (Butcher \& Schneider, 1998). The school must be able to fulfil this function, centred on the renewed relationship with sport and its institutions, which allows the new generations to approach, on the one hand, the promotion of Physical Literacy, a key opportunity to generate significant benefits in specific and transversal (Whitehead, 2010) and on the other to the great theme of the capitalization of human skills, in which fair play represents one of the main educational devices.

\section{REFERENCES}

Arnold P.J. (2002). Educazione motoria, sport e curriculo. Milano: Edizioni Angelo Guerini e Associati Spa.

Barthes R. (2007). Lo sport e gli uomini. Torino: Einaudi, pp. 47 - 49.

Bauman Z. (2018). Di nuovo soli. Un'etica in cerca di certezze. Roma: Castelvecchi, pp. 35-40; 51-57. 
Butcher R.\& Schneider A. (2007) Fair play as respect for the game in Journal Ethics in Sport, Human Kinetics Publishers, Ed.2, pp.119-140.

CIFP, International committee for fair play. www.fairplayinternational.org/home

Comité International Olympique, édité par le Comité International Olympique - Septembre 2013 https://www.olympic.org/

CONI - Comitato Olimpico Nazionale Italiano. Codice europeo di Etica sportiva, Consiglio d'Europa, Rodi, 13-15 maggio 1992. www.coni.it/images/documenti/Carta_europea_dello_Sport.pdf

D'Elia, F. (2020). Teachers' perspectives about contents and learning aim of physical education in Italian primary school, Journal of Human Sport and Exercise, 15 (Proc2), pp. S279-S288. https://doi.org/10.14198/ihse.2020.15.Proc2.19

D'Elia, F. (2019). The core curriculum of university training to teach physical education in Italy, Journal of Physical Education and Sport, 19, pp. 1755-1758.

Dichiarazione del Panathlon International sull'etica nello sport giovanile. http://www.panathloninternational.org/index.php/it-it/64-carte/222-dichiarazione-del-panathlon-sull-etica-nello-sportgiovanile-it

Elias N. \& Dunning E. (1985). Sport e aggressività. Bologna: II Mulino.

Farinelli G. (2005). Pedagogia dello sport e educazione della persona. Perugia: edizioni Morlacchi.

Federici A. \& Cocco F. (2020.) I doveri del genitore nello sport: i valori per un'educazione consapevole. In: La società per la società: ricerca, scenari, emergenze sull'educazione motoria e sportiva. Atti del Convegno Internazionale SIRD, Roma 26-27 settembre 2019, Lecce: Pensa Multimedia, pp.60-68.

Federici A. \& Cocco F. (2019). I Giovani e l'Etica Sportiva: un investimento dalla scuola alla società. In: Formazione \& Insegnamento, XVII, 1, Lecce: Pensa Multimedia Editore, pp. 89 - 100.

Guttman A. (1994). Da Ritual a Record: The Nature of Modern Sports, New York, Columbia University Press, 1978. Trad. it:: Dal rituale alla registrazione: la natura degli sport moderni. Napoli: Edizioni Scientifiche Italiane.

Greco G. (2004) L'avvento della società mediale. Riflessioni su politica, sport, educazione. Milano: Franco Angeli, p. 55.

Heinemann K. \& Puig N. (1996). Lo sport verso il 2000. Trasformazioni dei modelli sportivi nelle società sviluppate, In: Sport \& Loisir.

Huizinga J. (2002). Homo Ludens. Tad. it di Arrigo Vita. Introduzione di U. Eco. Torino: Piccola Biblioteca Einaudi NS.

MIUR, Indicazioni nazionali (2012) - Scuola Primo Ciclo.

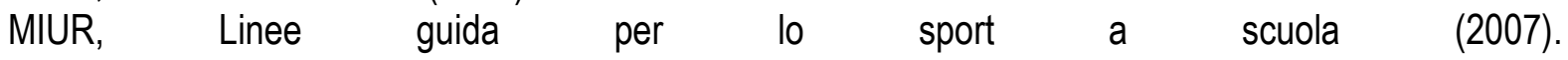
https://archivio.pubblica.istruzione.it/ministro/comunicati/2007/090207.shtml

MIUR, Indicazioni nazionali per i Piani di studio personalizzati nella Scuola Secondaria di $1^{\circ}$ grado (2003).

MIUR, D.M. 9 febbraio 1979 Programmi, orari di insegnamento e prove di esame per la scuola media statale.

MIUR, D.P.R. 12 febbraio 1985, n. 104. Approvazione dei nuovi programmi didattici per la scuola primaria.

MIUR, D.P.R. 15 marzo 2010, n. 89. Indicazioni nazionali per i percorsi liceali.

Monti, F., Farné, R., Crudeli, F., Agostini, F., Minelli, M., Ceciliani, A. (2019) The role of Outdoor Education in child development in Italian nursery schools, Early Child Development and Care, 189 (6), pp. 867-882. https://doi.org/10.1080/03004430.2017.1345896

ONU - Carta dei diritti dei ragazzi allo sport 1992. Commissione Tempo Libero. 
Pignato S., Tortella P., Coppola R., \& Schembri S. (2020) Sport, educazione e fair play. In: La società per la società: ricerca, scenari, emergenze sull'educazione motoria e sportiva. Atti del Convegno Internazionale SIRD, Roma 26-27 settembre 2019, Lecce: Pensa Multimedia, pp.102-111.

Pignato S. (2019). II valore educativo del fair play. In: Formazione \& Insegnamento, XVII, 3s, Pensa Multimedia, pp. 169-179.

Raiola, G. (2020a). The Movement and Sport Science in Italy towards the European Research Council, Physical Culture and Sport, Studies and Research, 86 (1), pp. 37-48. https://doi.org/10.2478/pcssr2020-0011

Raiola, G. (2020b). Proposal of rearrangement of physical training and sport sciences methodology academic disciplines in Italian university body. Sport Science, 14 (1), pp. 43-47.

Russo, G., Nigro, F., Raiola, G., Ceciliani, A. (2019a). The role of the extra physical activity on memory storage and psychosocial features, Journal of Human Sport and Exercise, 14 (Proc4), pp. S948S956. https://doi.org/10.14198//hse.2019.14.Proc4.57

Russo, G., Nigro, F., Raiola, G., Ceciliani, A. (2019b). Self-esteem in physically active middle school students, Journal of Physical Education and Sport, 19, art. no. 295, pp. 1984-1988.

Sandford, R.A., Armour, K.M., \& Warmington, PC. (2006). Re-engaging disaffected youth through physical activity programmes. British Educational Research Journal, 32, 251-271. https://doi.org/10.1080/01411920600569164

Schembri, R., Quinto, A., Aiello, F., Pignato, S., \& Sgrò, F. (2019). The relationship between the practice of physical activity and sport and the level of motor competence in primary school children. Journal of Physical Education and Sport, 19, 1994-1998.

Sgrò, F., Barca, M., Schembri, R., \& Lipoma, M. (2020). Assessing the effect of different teaching strategies on students' affective learning outcomes during volleyball lessons. Journal of Physical Education and Sport, 20, 2136-2142.

Tortella, P., Haga, M., Ingebrigtsen, J. E., Sigmundsson, H., \& Fumagalli, G. F. (2019). Comparing free play and partly structured play in 4-5-years-old children in an outdoor playground. Frontiers in public health, 7, 197. https://doi.org/10.3389/fpubh.2019.00197

Tortella, P. \& Fumagalli, G. (2017). The effect of teaching methodologies in promoting physical and cognitive development in children. Physical Activity and Educational Achievement: Insights from Exercise Neuroscience, 297, 303-316. https://doi.org/10.4324/9781315305790-17

Whitehead, M. (2010). The Concept of Physical Literacy. In M. Whitehead (Ed.), Physical Literacy throughout the Life Course. Abingdon, Oxford: Routledge. https://doi.org/10.4324/9780203881903

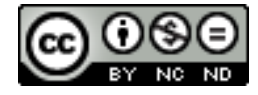

This work is licensed under a Attribution-NonCommercial-NoDerivatives 4.0 International (CC BY-NC-ND 4.0). 